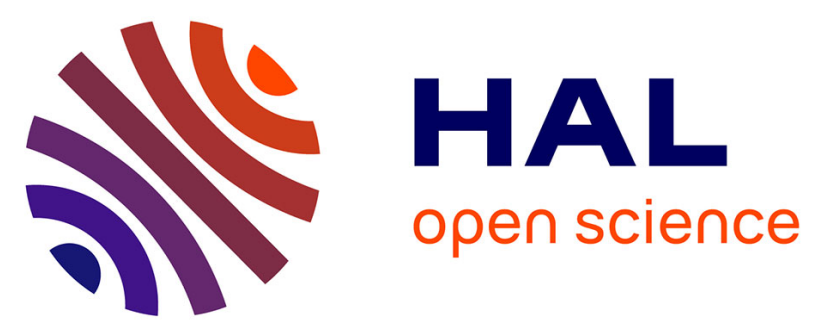

\title{
Freely adjusted properties in Ge-S based chalcogenide glasses with iodine incorporation
}

Minming Zhu, Xunsi Wang, Chen Jiang, Huijuan Xu, Qiuhua Nie, Peiquan Zhang, Shixun Dai, Xiang Shen, Tiefeng Xu, Guangming Tao, et al.

\section{- To cite this version:}

Minming Zhu, Xunsi Wang, Chen Jiang, Huijuan Xu, Qiuhua Nie, et al.. Freely adjusted properties in Ge-S based chalcogenide glasses with iodine incorporation. Infrared Physics and Technology, 2015, 69, pp.118-122. 10.1016/j.infrared.2015.01.015 . hal-01220891

\section{HAL Id: hal-01220891}

\section{https://hal-univ-rennes1.archives-ouvertes.fr/hal-01220891}

Submitted on 4 Nov 2015

HAL is a multi-disciplinary open access archive for the deposit and dissemination of scientific research documents, whether they are published or not. The documents may come from teaching and research institutions in France or abroad, or from public or private research centers.
L'archive ouverte pluridisciplinaire HAL, est destinée au dépôt et à la diffusion de documents scientifiques de niveau recherche, publiés ou non, émanant des établissements d'enseignement et de recherche français ou étrangers, des laboratoires publics ou privés. 


\title{
Freely Adjusted Properties in Ge-S based Chalcogenide Glasses with Iodine Incorporation
}

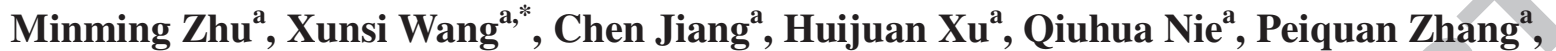 \\ Shixun Dai ${ }^{\mathrm{a}}$, Xiang Shen ${ }^{\mathrm{a}}$, Tiefeng Xua ${ }^{\mathrm{a}}$, Guangming Tao ${ }^{\mathrm{b}}$, and Xianghua Zhang \\ ${ }^{a}$ Laboratory of Infrared Material and Devices, Ningbo University, Ningbo, Zhejiang 315211, \\ China \\ ${ }^{b}$ CREOL, The College of Optics \& Photonics, University of Central Florida, Orlando, FL 32816 \\ United State \\ ${ }^{c}$ Laboratory of Glasses and Ceramics, UMR 6226 CNRS-University of Rennes 1, Rennes Cedex \\ 135042, France
}

Abstract: In this study, we examined the function of halogen iodine acting as a glass network modifier in green chalcogenide glasses based on the Ge-S system. We obtained a series of Ge-S-I glasses and determined their glass-forming region. We then recorded the physical, thermal, and optical properties and studied the effect of halogen iodine on Ge-S-I glasses. Results show that these glasses have relatively wide optical transmission window for infrared (IR) applications. The softening temperature of Ge-S-I glasses varies from $210.54^{\circ} \mathrm{C}$ to $321.63^{\circ} \mathrm{C}$, this temperature fits well with some kinds of high-temperature polymers, such as PES and PEI, the polymers serve as protective layers with high strength and flexibility, thus simplifying the fabrication processes of IR chalcogenide glass fiber. Finally, we performed a purification process to eliminate impurities and to improve optical spectra.

Key words: Chalcogenide glass; Purification; Optical fiber.

1

*Corresponding author .Tel: +86 5748760 0947; fax: +86 57487600946.

E-mail address: xunsiwang@ siom.ac.cn (X.S. Wang). 


\section{Introduction}

Halide and chalcogenide glasses have attracted considerable attentionas potential candidates for material transmission in the mid-infrared (IR)region[1-3]. Halide glasses have ultra-low loss in mid-IR but have poor chemical resistance[4]. Chalcogenide glasses have high transition temperature $\left(T_{\mathrm{g}}\right)$, as well as good chemical and thermal stability. However, high optical transmission loss limited the application of chalcogenide glasses in long-distance fiber communication or fiber sensing because of several intrinsic defects in their net-structure[5]. Therefore, a type of chalcohalide glass $(\mathrm{CHG})$ with the integrated advantages of low-loss halide glass fiber, high chemical stability, and good anticrystallization was developed. CHG can enhance the compactness of the glass network, improve glass anticrystallization, and significantly increase glass-forming capability. Moreover, halogen or halide with low melting temperature and low refractive index can be introduced into chalcogenide glasses to improve the glass and optical spectra properties[4]. Numerous studies have reported on the advantages of CHGs[4, 6-8], particularly rare earth-doped CHGs. However, few studies have been conducted on the CHG fiber and its fabrication processes.

Arsenic sulfide has outstanding properties in terms of fiber drawing feasibility but is environmentally toxic. Ge-S glass is good for the environment, has high chemical and mechanical stability, and is easy to prepare with high purity[9]. Ge-S has a strong crystallization tendency. In addition, $\mathrm{As}_{2} \mathrm{Se}_{3}$ and $\mathrm{As}_{2} \mathrm{~S}_{3}$ glasses are suitable for polyethersulfone or polyetherimide[10]. However, high-temperature polymers that fit chalcogenide glasses are difficult to find, especially for Ge-S based glasses, because of their relatively high $T_{\mathrm{g}}$. We 
prepared Ge-S based CHGs with halogen iodine to fabricate low-loss $\mathrm{CHG}$ fiber. We then investigated the effect of halogen on the chemical, physical, thermal, and optical properties of CHGs in Ge-S-I systems in detail.

A wide range of unique devices have been developed with the use of a special optical fiber or through the same fiber-forming strategy of combining multiple materials with disparate optical, electronic, and thermomechanical properties monolithically. These methods suggest new ways to leverage the fiber drawing process as a fabrication methodology[11]. This method includes the investigation of the nonlinear characteristics of a new class of robust, multimaterial, and all-solid chalcogenide nanotapers prepared from high-index-contrast chalcogenide fibers. Another step is the generation of the IR super continuum extending over more than one octave of bandwidth, produced in a single spatial mode from a robust, compact, and composite chalcogenide glass nanotaper and zero-GVD, high-index contrast, all-solid CHG fibers for IR nonlinear fiber optics. The process of rolling and covering glasses with high-strength polymer strengthens fragile $\mathrm{CHG}$ glass fibers. Glass and polymer stick together tightly under a high-temperature and vacuum environment, thereby removing water in the process. Hence, additional work has to be performed to decrease the glass softening temperature $\left(T_{\mathrm{p}}\right)$ to fit high-strength polymer. This process provides protection for the fiber and increases the feasibility of CHG fiber fabrication.

\section{Experimental}

Bulk glasses were prepared by using a traditional melt-quenching method. Elemental raw 
materials of high-purity Ge and S(99.99\%) and I(99.9\%) were carefully weighed and transferred into quartz ampoules that were then sealed under a vacuum of air pressure $\left(2 \times 10^{-3} \mathrm{~Pa}\right)$. The investigated compositions in this glass system are as follows: series $A, G_{25} S_{75-x} I_{x}$ $(x=2,5,8,10,15,20,25,30)$; series $\mathrm{B},\left(\mathrm{GeS}_{3}\right)_{100-x} \mathrm{I}_{x}(x=5,10,12,13,15,20)$. Iodine is volatile at room temperature. Hence, the materials in the ampoules should be cooled by liquid nitrogen during the vacuum evacuation process. The quart ampoules containing the raw materials were heated slowly in a rocking furnace to $800^{\circ} \mathrm{C}$ at a rate of $5 \mathrm{Kmin}^{-1}$ and maintained at this temperature for 24h. Then the ampoules were quenched in water and swiftly moved to a preheated furnace to anneal at $10^{\circ} \mathrm{C}$ below $T_{\mathrm{g}}$ for $4 \mathrm{~h}$ to minimize inner tension. Glass rods were taken from the ampoules, cut into disks, and then polished for testing. The melting and fabricating conditions are nearly the same, and all of the samples were processed into $2 \mathrm{~mm}$ with precise polishing.

All optical tests were conducted at room temperature. Densities were measured according to the Archimedes principle, and the accuracy was $\pm 0.001 \mathrm{~g} / \mathrm{cm}^{3} . T_{\mathrm{g}}$ and $T_{\mathrm{p}}$ were determined in the temperature range of $40^{\circ} \mathrm{C}$ to $450^{\circ} \mathrm{C}$ at a heating speed of $4^{\circ} \mathrm{C} / \mathrm{min}$ using Netzsch DIL402 thermal dilatometer, and the accuracy was $\pm 1.0^{\circ} \mathrm{C}$. The visible absorption spectra of glass samples were recorded in the range of $400 \mathrm{~nm}$ to $2500 \mathrm{~nm}$ using Perkin-Elmer Lambda 950 UV-Vis-NIR spectrophotometer. The IR transmission spectra of glass samples were obtained in the range of $4000 \mathrm{~cm}^{-1}$ to $400 \mathrm{~cm}^{-1}$ using the Nicolet 380 Fourier Infrared spectrophotometer. SAIRON SPA4000 Prism coupling instrument was used to measure the refractive index of the glasses. 


\section{Results and discussions}

On the basis of the two glass-forming regions (GFRs) of Ge-S $\mathrm{S}_{1.31-1.50}$ and $\mathrm{Ge}-\mathrm{S}_{2.0-9.0}$ in the

Ge-S binary system of Kawamoto and Tsuchihashi[12], we obtained an expanded ternary GFR of the Ge-S-I system by quenching a series of $8 \mathrm{~g}$ melts in water (Fig.1). The results show a limited but detailed distribution of GFR in the Ge-S-I system. Iodine was added as a substitute for sulfur. Therefore, some of the bridging sulfur chains are released and self-polymerized to form $\mathrm{S}_{8}$ rings[7]. $\mathrm{Ge}_{25} \mathrm{~S}_{75-x} \mathrm{I}_{x}$ glasses are formed together stability. The GFR also presents the states of anticrystallization while iodine content is 2 and 30. Meanwhile, an optimized glass-forming line is found in the GFR with good glass stability and anti-hygroscopicity, as shown in glass series $\mathrm{B}\left[\left(\mathrm{GeS}_{3}\right)_{100-x} \mathrm{I}_{x}\right]$.

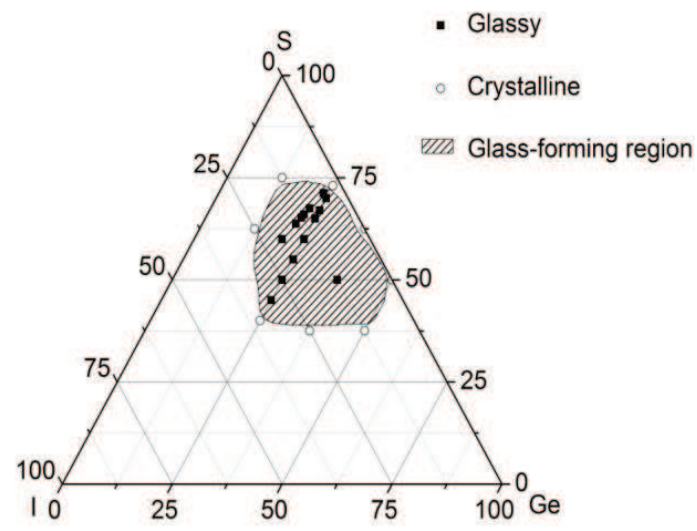

Fig.1 GFR in the Ge-S-I ternary

\subsection{Physical properties}

Table 1 lists the components and physical properties of the analyzed glass samples. The 
measured density $(\rho)$ of the glasses increases linearly as the iodine content in series A and B increases. The observed density increase in both systems is primarily attributed to the large difference in atomic mass between sulfur and iodine. An increase in total mass by the substitution of relatively light sulfur atoms with heavy halogen atoms results in avariation of the dominant glass netstructure. The atomic weights of $\mathrm{Ge}, \mathrm{S}$, and I are $72.6,32$, and 127, respectively. Thus, the increase in iodine content is responsible for the increase in glass density. The density of a given composition can be calculated by using the following formula:

$$
\rho=\Sigma_{i} M_{i} / V_{m}
$$

Where $M_{i}$ denotes the molar mass of the glass, $M_{i}=C_{i} A_{i}\left(C_{i}\right.$ isthe molar concentration, and $A_{i}$ is the molecular weight of the component).

Table 1 Physical and thermal properties of Ge-S-I glasses

\begin{tabular}{ccccccc}
\hline Composition & $n, 632.8 \mathrm{~nm}$ & $n, 1310 \mathrm{~nm}$ & $n, 1550 \mathrm{~nm}$ & $T_{\mathrm{g}}\left({ }^{\circ} \mathrm{C}\right)$ & $T_{\mathrm{p}}\left({ }^{\circ} \mathrm{C}\right)$ & $\rho\left(\mathrm{g} / \mathrm{cm}^{3}\right)$ \\
\hline$\left(\mathrm{GeS}_{3}\right)_{95} \mathrm{I}_{5}$ & 2.0891 & 2.0186 & 2.0122 & 250.23 & 321.63 & 2.7616 \\
$\left(\mathrm{GeS}_{3}\right)_{90} \mathrm{I}_{10}$ & 2.0782 & 2.0071 & 2.0066 & 208.82 & 269.05 & 2.9317 \\
$\left(\mathrm{GeS}_{3}\right)_{88} \mathrm{I}_{12}$ & 2.0752 & 2.0046 & 2.0034 & 195.24 & 277.34 & 3.0193 \\
$\left(\mathrm{GeS}_{3}\right)_{87} \mathrm{I}_{13}$ & 2.0690 & 1.9962 & 1.9864 & 178.63 & 246.46 & 3.0852 \\
$\left(\mathrm{GeS}_{3}\right)_{85} \mathrm{I}_{15}$ & 2.0630 & 1.9898 & 1.9791 & 166.62 & 221.14 & 3.2003 \\
$\left(\mathrm{GeS}_{3}\right)_{80} \mathrm{I}_{20}$ & 2.0494 & 1.9685 & 1.9604 & 141.35 & 204.13 & 3.4325 \\
$\mathrm{Ge}_{25} \mathrm{~S}_{70} \mathrm{I}_{5}$ & 2.0911 & 2.0891 & 2.0814 & 285.53 & 337.25 & 2.8139 \\
$\mathrm{Ge}_{25} \mathrm{~S}_{67} \mathrm{I}_{8}$ & 2.0826 & 2.0630 & 2.0593 & 245.53 & 300.01 & 2.9547 \\
$\mathrm{Ge}_{25} \mathrm{~S}_{65} \mathrm{I}_{10}$ & 2.0785 & 2.0586 & 2.0541 & 220.21 & 271.23 & 3.0021 \\
$\mathrm{Ge}_{25} \mathrm{~S}_{60} \mathrm{I}_{15}$ & 2.0653 & 2.0332 & 2.0251 & 196.62 & 256.36 & 3.2519 \\
$\mathrm{Ge}_{25} \mathrm{~S}_{55} \mathrm{I}_{20}$ & 2.0561 & 1.9875 & 1.9805 & 183.99 & 235.73 & 3.3538 \\
$\mathrm{Ge}_{25} \mathrm{~S}_{50} \mathrm{I}_{25}$ & 2.0484 & 1.9772 & 1.9770 & 179.78 & 210.54 & 3.5466 \\
\hline
\end{tabular}

\subsection{Thermal properties}

We investigated the thermal characteristics of glass samples by using a thermal dilatometer.

Table 1 lists the $T_{\mathrm{g}}$ and $T_{\mathrm{p}}$ values. We observed and recorded two main trends according to series 
115

A and B. All glasses were found to exhibit a single glass transition and a single crystallization peak, which exhibited good unit in coordination with the chemically bonded phases of Ge, S, and I in terms of synthesizing glass. The addition of iodine decreased $T_{\mathrm{g}}$ for all glass systems. Thus, $T_{\mathrm{g}}$ and $T_{\mathrm{p}}$ gradually decreased as iodine increased because of the low melting point of halogen iodine.

Iodine ions have the effect of terminating the network, decreasing the average bond strength in the glasses. The amount of bridging sulfur would reduce because of the formation of new Ge-I bonds, and the amorphous network would start to lose its three-dimensional connectivity. A larger number of substitutions occurred as more iodine was eventually added. This result gave rise to a novel form of chain-structured[6] glass network and improved glass thermostability. Therefore, the physical and chemical properties of the glasses are determined by the rate of Ge-S, and the glass-forming capability is based on the iodine content of in Ge-S-I glasses.

The free adjustment of $T_{\mathrm{g}}$ and $T_{\mathrm{p}}$ with iodine incorporation provides facilitates the exploration of high-strength chalcogenide glass fibers with a protective polymer jacket. Table 2 presents a series of Ge-S-I glasses that fits commercial polymers. The chalcogenide glass fiber is easily prepared and has an extended application because it is protected by a matching high-strength polymer. Fig.2 shows the polymer rolling and fiber drawing processes, and Refs. $[10,13]$ discuss the details. 


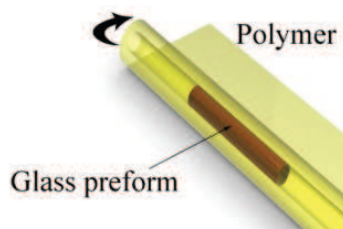

i

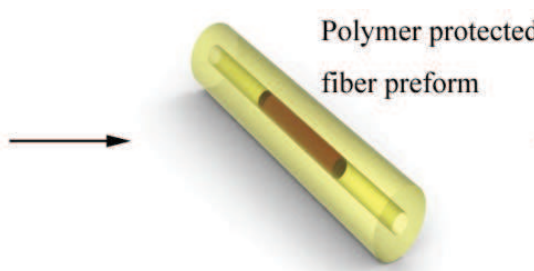

ii

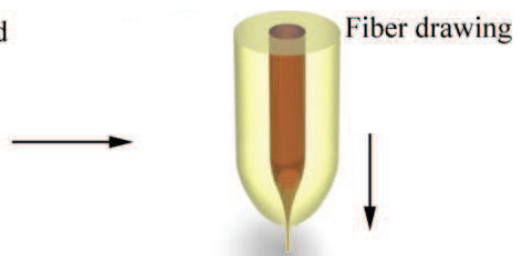

iii

Fig.2 Main processes for the fabrication of polymer-protected fiber preform and fiber drawing

Table 2 Thermal properties of glasses with matching polymers

\begin{tabular}{ccc}
\hline Polymer & Temperature $\left({ }^{\circ} \mathrm{C}\right)$ & Matched glasses \\
\hline Polyimide(PI) & $250-340\left(T_{\mathrm{g}}\right)$ & $\left.\mathrm{Ge}_{25} \mathrm{~S}_{67} \mathrm{I}_{8}, \mathrm{GeS}_{3}\right)_{95} \mathrm{I}_{5}$ \\
Polyethersulfone(PES) & $225\left(T_{\mathrm{g}}\right)$ & $\mathrm{Ge}_{25} \mathrm{~S}_{65} \mathrm{I}_{10}$ \\
Polyetherimide(PEI) & $217\left(T_{\mathrm{g}}\right)$ & $\mathrm{Ge}_{25} \mathrm{~S}_{65} \mathrm{I}_{10}$ \\
Polysulfone(PSU) & $190\left(T_{\mathrm{g}}\right)$ & $\left(\mathrm{GeS}_{3}\right)_{88} \mathrm{I}_{12}, \mathrm{Ge}_{25} \mathrm{~S}_{60} \mathrm{I}_{15}$ \\
Poly(etherketone) (PEK) & $162\left(T_{\mathrm{g}}\right)$ & $\left(\mathrm{GeS}_{3}\right)_{85} \mathrm{I}_{15}$ \\
Polycarbonate(PC) & $150\left(T_{\mathrm{g}}\right)$ & $\left(\mathrm{GeS}_{3}\right)_{80} \mathrm{I}_{20}$ \\
Polyetheretherketone & $148\left(T_{\mathrm{g}}\right)$ & $\left(\mathrm{GeS}_{3}\right)_{80} \mathrm{I}_{20}$ \\
(PEEK) & $332\left(T_{\mathrm{p}}\right)$ & \\
PTFE & $316\left(T_{\mathrm{p}}\right)$ & $\left(\mathrm{GeS}_{3}\right)_{95} \mathrm{I}_{5}$ \\
cPTFE & $270\left(T_{\mathrm{p}}\right)$ & $\left(\mathrm{GeS}_{3}\right)_{95} \mathrm{I}_{5}$ \\
FEP & $306\left(T_{\mathrm{p}}\right)$ & $\left(\mathrm{GeS}_{3}\right)_{88} \mathrm{I}_{12}, \mathrm{Ge}_{25} \mathrm{~S}_{65} \mathrm{I}_{10}$ \\
PFA & $257\left(T_{\mathrm{p}}\right)$ & $\mathrm{Ge}_{25} \mathrm{~S}_{67} \mathrm{I}_{8}$ \\
ETFE & $177\left(T_{\mathrm{p}}\right)$ & $\mathrm{Ge}_{25} \mathrm{~S}_{60} \mathrm{I}_{15}$ \\
PVDF & $196\left(T_{\mathrm{p}}\right)$ & - \\
PVF & $70-155\left(T_{\mathrm{g}}\right)$ & $\left(\mathrm{GeS}_{3}\right)_{80} \mathrm{I}_{20}$ \\
Cyclic olefin copolymer & & $\left(\mathrm{GeS}_{3}\right)_{80} \mathrm{I}_{20}$ \\
(COC) & \\
\hline
\end{tabular}

\subsection{Refractive index}

The refractive index of glasses is measured using SPA4000 Prism coupling instrument at $632.8,1310$, and $1550 \mathrm{~nm}$. The refractive index $n$ is generally determined by the ionic polarization and the density of the glass. Ionic polarization occurs as light is transmitted through the glass. Such transmission consequently affects the speed of light, which determines the 
refractive index of the glasses. The refractive index of the glasses decreases as iodine atoms are added into the Ge-S systems. This effect decreases glass network connectivity because of the incorporation of network-terminating iodine atoms[14, 15], which weaken the average bond strength of the glasses. In addition, the density of glass affects the refractive index. The glass refractive index gradually decreases as iodine under a same type of glass host increases.

\subsection{Vis-NIR absorption edges and optical band gap}

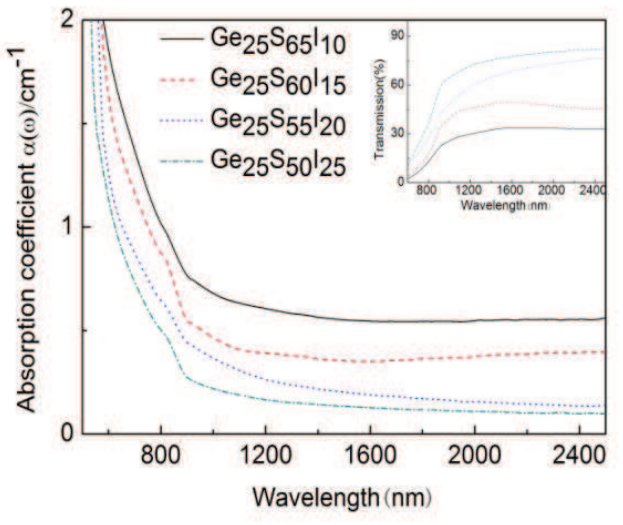

(a)

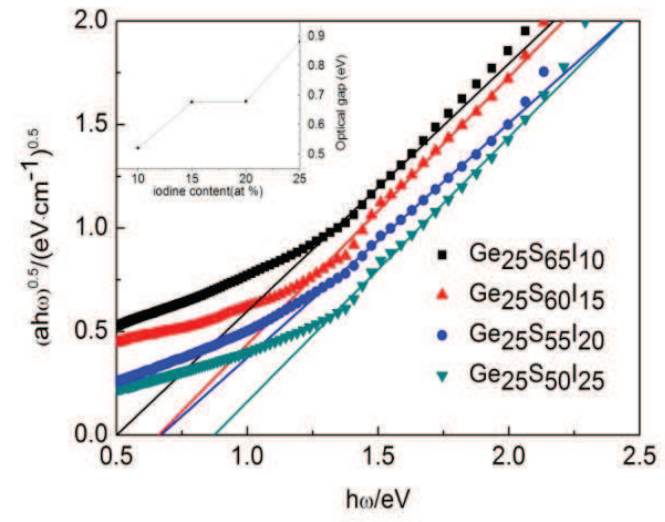

(b)

Fig.3 (a) Near-IR absorption spectra of the Ge-S-I glass samples. (b) Relationship between $\alpha h \omega^{0.5}$ and $h \omega$ for glass samples; upper-left inset shows the relationship between indirect optic gap $E_{\text {opt }}$ and iodine content.

Fig,3(a) illustrates the Vis-NIR absorption spectra for the glasses with different iodine contents. Fig.3(a) insert shows the dependence of short-wave cutoff edge $\left(\lambda_{\text {vis }}\right)$ on heavy metal halide content for $\mathrm{Ge}_{25} \mathrm{~S}_{75-x} \mathrm{I}_{x}$ glasses. $\lambda_{\text {vis }}$ gradually shifts to a shorter wavelength as iodine increases. Some sulfur ions at the end of the Ge-S netchain are replaced by iodine ions. A higher excitation energy of light is needed for a stronger binding energy between cation and anion ions. Hence, the optical cut off edge is shorter. Iodine can cause the lower sideband of the valance 
band to drift directly toward a lower energy band because it is negatively charged and electrophilic. Table 3 shows that the optical band gap energy increases as iodine content increases although the conduct band changes insignificantly.

Table 3 Indirect optical gap and IR transmission of $\mathrm{Ge}_{25} \mathrm{~S}_{75-x} \mathrm{I}_{x}$ glasses

\begin{tabular}{ccc}
\hline Glasses & Indirect optical gap $(\mathrm{eV})$ & Transmission $(\%)$ at $9 \mu \mathrm{m}$ \\
\hline $\mathrm{Ge}_{25} \mathrm{~S}_{65} \mathrm{I}_{10}$ & 0.520 & 34.36 \\
$\mathrm{Ge}_{25} \mathrm{~S}_{60} \mathrm{I}_{15}$ & 0.676 & 41.95 \\
$\mathrm{Ge}_{25} \mathrm{~S}_{55} \mathrm{I}_{20}$ & 0.678 & 50.07 \\
$\mathrm{Ge}_{25} \mathrm{~S}_{50} \mathrm{I}_{25}$ & 0.880 & 68.08 \\
\hline
\end{tabular}

\subsection{IR optical transmission}

Fig.4 shows the IR transmission spectra of some typical glass samples. These samples have excellent transparency in the IR region wavelength. The IR transmittance ratio changes considerably as the iodine content varies. The phonon energy depends on the strength of the chemical bond and the weight of the atoms. Iodine can open the structure of $\mathrm{Ge}_{25} \mathrm{~S}_{75-x} \mathrm{I}_{x}$ glasses. Hence, the highest transmission ratio can be achieved with the $\mathrm{Ge}_{25} \mathrm{~S}_{50} \mathrm{I}_{25}$ composition. The decrease in refractive index can slightly improve the transmission ratio. However, Fig.4 shows that other reasons, such as the effect of reflection, scatter, absorption, and other factors in IR transmission, should be present. The most important reason may be the improvement of the glass network with iodine, which serves as an adjuster to decrease the defect of glass network and to cut down the value of the weak absorption tail of glass gradually. The available transmission IR cut off waveleng this generally determined by the molecular vibrational spectroscopy of glass network formers, which is called glass phonon energy. Owing to the glass network former[16] of 
Ge-S and the addition of iodine (some sulfur is partly replaced by iodine), glass network connectivity is significantly strengthened. Thus, optical transparency is improved while keeping a nearly similar IR cutoff wavelength under nearly the same phonon energy.

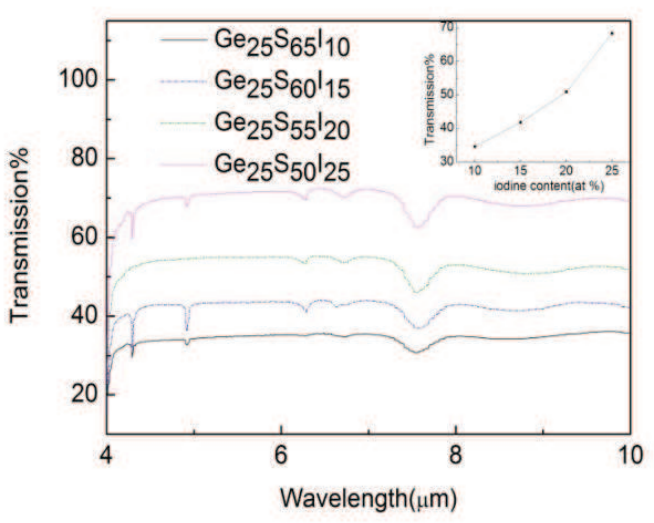

Fig.4 IR transmission spectra of some Ge-S-I glasses

We performed an additional purification process to improve the quality of glass $\mathrm{Ge}_{25} \mathrm{~S}_{60} \mathrm{I}_{15}$. We heated the selected glass composition and its raw materials at to $200^{\circ} \mathrm{C}$ to be under an evacuated vacuum condition to remove reduced water, as shown in Fig.5(a). Ge and S, Mg, or $\mathrm{AlCl}_{3}$ were all placed into the left quartz tube to remove impurities, where as I was placed in the right quartz tube under liquid $\mathrm{N}_{2}$ cooling during the vacuum evacuation process. The middle of the quartz tube was welded using anoxy-acetylene flamer and formed an $\mathrm{H}$-shaped silica vessel after the raw materials transferred into the quartz tube. Then the $\mathrm{H}$-shaped tube was sealed under a vacuum of $2 \times 10^{-3} \mathrm{~Pa}$ at the point of 1 , as shown in Fig.5(b). The left quartz tube was heated to $1200{ }^{\circ} \mathrm{C}$ with a fast-heating furnace. The raw materials of $\mathrm{Ge}$ and $\mathrm{S}$ or glasses were distilled into the right quartz tube gradually with the help of high temperature. Oxide and other particles remained in the left tube, and then the tube was sealed by oxy-acetylene flamer at point 2 , as 
shown in Fig.5(b). Finally, the quartz tube was heated slowly at $800^{\circ} \mathrm{C}$ in a rocking furnace at a rate of $5 \mathrm{Kmin}^{-1}$, as mentioned previously.

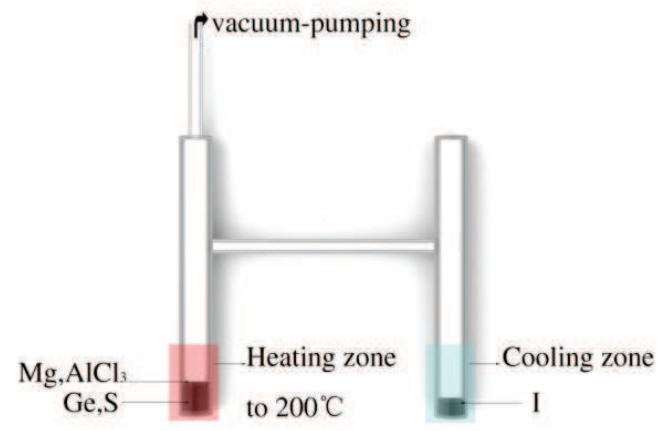

(a)

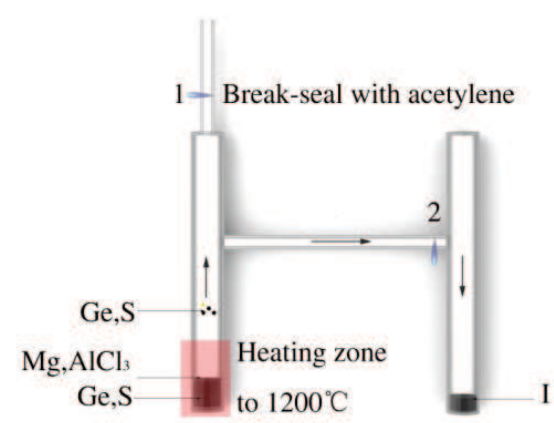

(b)

Fig.5 Purification processes of Ge-S-I glasses:(a) evacuation process and(b) seal and purification processes

Fig.6 shows the comparisons between the bulk glass synthesized with as-received chemicals and the purified glass. Table 4 shows that impurity losses attributed to the fundamental $\mathrm{H}-\mathrm{S}$ vibrational band $(3.96 \mu \mathrm{m})[17], \mathrm{H}-\mathrm{S}$ combinational bands $(3.78 \mu \mathrm{m})[18]$, and carbon impurity $(4.92 \mu \mathrm{m})[18]$ are noticeable in the low purity glass. Fig.6(b) shows that impurity-related vibrational $\mathrm{H}_{2} \mathrm{O}(6.32 \mu \mathrm{m})$ and $\mathrm{C}$ absorption bands $(4.92 \mu \mathrm{m})$ are eliminated effectively by using purified chemicals because the raw materials in the process of vacuum evacuation can not be heated because of the volatility of iodine[19]. Moreover, the absorption peak of S-H, Ge-H, and $\mathrm{Ge}-\mathrm{O}$ has a clear improvement. The absorbance coefficients of $\mathrm{S}-\mathrm{H}, \mathrm{Ge}-\mathrm{H}$, and $\mathrm{Ge}-\mathrm{O}$ are lower (more transparent) than that of the original. This method can compensate for the shortage of liquid $\mathrm{N}_{2}$ during the cooling condition in the vacuum evacuation process. This method will also keep all the extracted water as solid ice mixed with glass raw material. However, more 
purification processes are needed to remove other impurities as well as the unbound water of the glass. Multiple distillations of the chemicals are also necessary to reduce the extrinsic scattering centers and to absorb impurities further. Therefore, this method provides a high probability for the fabrication of high-purity chalcogenide optical glass or fiber.

215

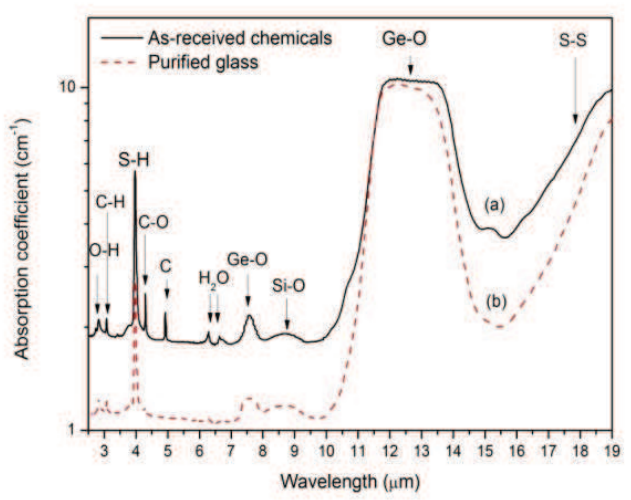

Fig.6 Absorbance coefficient plot for (a) glass $\mathrm{Ge}_{25} \mathrm{~S}_{60} \mathrm{I}_{15}$ made from as-received chemicals and (b)

glass $\mathrm{Ge}_{25} \mathrm{~S}_{60} \mathrm{I}_{15}$ made from partially purified chemicals with $500 \mathrm{ppm} \mathrm{Mg}$ as an oxide scavenging agent.

Table 4 Extrinsic absorption bands of selected oxides and hydride impurities

\begin{tabular}{ccc}
\hline Impurities & Absorption wavelength $(\mu \mathrm{m})$ & Reference \\
\hline $\mathrm{O}-\mathrm{H}$ & $3.06 \mathrm{~m}, 2.82 \mathrm{~m}$ & {$[18]$} \\
$\mathrm{H}_{2} \mathrm{O}$ & $6.62 \mathrm{w}, 6.28 \mathrm{~m}$ & {$[18]$} \\
$\mathrm{S}-\mathrm{H}$ & $3.96 \mathrm{vs}, 3.78 \mathrm{~m}$ & {$[17]$} \\
$\mathrm{Si}-\mathrm{O}$ & $8.7 \mathrm{~m}$ & Fundamental \\
$\mathrm{Ge}-\mathrm{O}$ & $12.5 \mathrm{vs}$ & Fundamental[20] \\
$\mathrm{Ge}-\mathrm{O}$ & $7.5 \mathrm{~s}$ & Over stone \\
$\mathrm{C}$ & $4.92 \mathrm{~s}$ & {$[18]$} \\
$\mathrm{C}-\mathrm{O}$ & $4.29 \mathrm{~s}$ & {$[18]$} \\
$\mathrm{C}-\mathrm{H}$ & $3.07 \mathrm{~m}$ & {$[18]$} \\
$\mathrm{S}-\mathrm{S}$ & $19 \mathrm{sh}$ & Multi-phonon \\
& & absorption \\
\hline
\end{tabular}


Intensity of absorption bands: vs,very strong; s,strong; m,middle; w,weak; sh,absorption shoulder.

221

222

223

224

\section{Conclusions}

In this study, we prepared aseries of Ge-S-I CHGs and investigated some key properties. Density increases while $T_{\mathrm{g}}, T_{\mathrm{p}}$, and refractive index $n$ decrease gradually as iodine increases. The short wavelength of $\lambda_{\text {vis }}$ shifts to shorter wavelength gradually as the halogen content increases for $\mathrm{Ge}_{25} \mathrm{~S}_{75-x} \mathrm{I}_{x}$ glasses. Iodine can open the structure of $\mathrm{Ge}-\mathrm{S}$, and $\mathrm{Ge}_{25} \mathrm{~S}_{50} \mathrm{I}_{25}$ has the highest transmission. The indirect optical gap and the cut off edge at $9 \mu \mathrm{m}$ increase as iodine increases from 10 to 25 for the $\mathrm{Ge}_{25} \mathrm{~S}_{75-x} \mathrm{I}_{x}$ glasses. These glasses have excellent transmission property in the IR region and possess great potential for future IR application. Moreover, a purification process was verified to eliminate the impurities effectively, particularly the unbound water and carbon particles of the glass. All this work significantly improved optical transmission. Owing to the freely adjusted thermal properties with the addition of iodine, commercial polymer can be adopted to protect chalcogenide glass-based fibers effectively because of the perfect suitability of these materials,

\section{Acknowledgments}

This work was financially supported by the National Program on Key Basic Research Project (973 Program) (Grant No. 2012CB722703), the Natural Science Foundation of China (Grant Nos. 61377099 and 61177087), the Scientific Research Fund of Zhejiang Provincial Education Department (R1101263), the Natural Science Foundation of Ningbo (Grant No. 2013A610118), 
the Teaching and Research Award Program for Outstanding Young Teachers in Higher Education Institutions of MOE, PRC, the Ningbo optoelectronic materials and devices creative team (2009B21007), the Scientific Research Foundation of Graduate School of Ningbo University, and the K. C. Wong Magna Fund in Ningbo University.

\section{References and links}

1. R. M. Almeida and J. D. Mackenzie, "The effects of oxide impurities on the optical properties of fluoride glasses," Journal of Non-Crystalline Solids 56(1), 63-68 (1983).

2. M. G. Drexhage, M. Tomozawa, and R. Doremus, Treatise on materials science and technology, Vol (26Academic Press, New York,1985).

3. M. Poulain, "Halide glasses," Journal of Non-Crystalline Solids 56(1), 1-14 (1983).

4. J. Sanghera, J. Heo, and J. Mackenzie, "Chalcohalide glasses," Journal of non-crystalline solids 103(2), 155-178 (1988).

5. D. Lezal, J. Pedlikova, and J. Zavadil, "Chalcogenide glasses for optical and photonics applications," J. Optoelectron. Adv. Mater 6(133-137 (2004).

6. J. Heo and J. D. Mackenzie, "Chalcohalide glasses: I. Synthesis and properties of Ge-S-Br and Ge-S-I glasses," Journal of non-crystalline solids 111(1), 29-35 (1989).

7. J. Heo and J. D. Mackenzie, "Chalcohalide glasses: II. Vibrational spectra of G- S-Br glasses," Journal of non-crystalline solids 113(1), 1-13 (1989).

8.A. Kut'in, A. Plekhovich, A. Vel'muzhov, and M. Churbanov, "Chemical and physical transformations in Ge-SI glass preparation," Inorganic Materials 48(4), 428-432 (2012). 
9. J. Kirchhof, J. Kobelke, M. Scheffler, and A. Schwuchow, “As-S based materials and fibres towards efficient $1.3 \mu$ m fibre amplification," Electronics Letters 32(13), 1220-1221 (1996).

10. G. Tao, S. Shabahang, E.-H. Banaei, J. J. Kaufman, and A. F. Abouraddy, "Multimaterial preform coextrusion for robust chalcogenide optical fibers and tapers," Optics letters 37(13), 2751-2753 (2012).

11. G. Tao, A. M. Stolyarov, and A. F. Abouraddy, "Multimaterial fibers," International Journal of Applied Glass Science 3(4), 349-368 (2012).

12.Y. Kawamoto and S. Tsuchihashi, "Glass $\square$ Forming Regions and Structure of Glasses in the System Ge $\square$ S,” Journal of the American Ceramic Society 52(11), 626-627 (1969).

13. E. Pone, C. Dubois, N. Gu, Y. Gao, A. Dupuis, F. Boismenu, S. Lacroix, and M. Skorobogatiy, Drawing of the hollow all-polymer Bragg fibers 2006).

14. J. Heo, H. Nasu, and J. D. Mackenzie, "Infrared transmitting chalcohalide glasses," in 30th Annual Technical Symposium, (International Society for Optics and Photonics, 1986), 85-91.

15. B. J. Riley and W. C. Lepry, Initial Assessment of the Consolidation of Chalcogels into a Viable Waste Form (Pacific Northwest National Laboratory,2012).

16. A. Seddon and M. Hemingway, "Thermal properties of chalcogenide-halide glasses in the system: Ge-SI,” Journal of Thermal Analysis and Calorimetry 37(9), 2189-2203 (1991).

17. S. Shibata, Y. Terunuma, and T. Manabe, "Sulfide glass fibers for infrared transmission," Materials Research Bulletin 16(6), 703-714 (1981).

18. T. Kanamori, Y. Terunuma, S. Takahashi, and T. Miyashita, "Chalcogenide glass fibers for mid-infrared transmission," Lightwave Technology, Journal of 2(5), 607-613 (1984). 
Photonica Sinca 37(S1), 1-7 (2008). Advanced Materials 5(1), 23-34 (2003). 